\title{
Experimental Investigation on the Effect of Reinforcement Particles on the Forgeability and the Mechanical Properties of Aluminum Metal Matrix Composites
}

\author{
S. Das, R. Behera, A. Datta, G. Majumdar, B. Oraon, G. Sutradhar* \\ Jadavpur University, Kolkata, West Bengal, India. \\ Email: Goutam_sutradhar@rediffmail.com \\ Received September $13^{\text {th }}, 2010$; revised November $1^{\text {st }}, 2010$; accepted November $6^{\text {th }}, 2010$.
}

\begin{abstract}
The wide choice of materials, today's engineers are posed with a big challenge for the right selection of a material and as well as the right selection of a manufacturing process for an application. Aluminium Metal Matrix Composites is a relatively new material among all the engineering materials. It has proved its position in automobile, aerospace, and many other engineering applications due its wear resistance properties and due to its substantial hardness. One of the most important criteria is forgeability by which the workability of the material can be determined. The nature of distribution of reinforcing phase in the matrix greatly influenced the properties of Aluminum Metal Matrix Composites. The forgeability of Aluminum Metal Matrix Composites, which are produced by powder metallurgy method, are greatly depends on the size and percentage of reinforcement materials, compacting load, sintering temperature and soaking time etc. In this present work, the forgeability of Aluminum Metal Matrix Composites reinforced with silicon carbide (400 meshes) has investigated. A comparison have been made with different types of Aluminum Silicon Carbide Metal Matrix Composite materials contains $0 \% 5 \%, 10 \%, 15 \% \& 20 \%$ by weight of silicon carbide. The mechanical properties like hardness of the different composites have also investigated. It is observed that the forgeabilty of the composites decreases with increasing the wt\% of SiC but the mechanical properties like hardness enhanced on increasing the wt\% of $\mathrm{SiC}$.
\end{abstract}

Keywords: Aluminium Metal Matrix Composites, Sic, Forgeabilty, Mechanical Properties

\section{Introduction}

Particle reinforced aluminium matrix composites (MMCs) have developed in the last few years, in order to reduce the weight of components in structural applications and to improve their mechanical properties and physical properties. Metal matrix composites are a class of material with the ability to blend the properties of ceramics (high strength and high modulus) with those of metals or alloys (ductility and toughness) to produce significant improvements in the mechanical performance of the composites over those of the monolithic metals or alloys [1]. During the past two decades, a lot of research has been devoted to controlling the size, shape, morphology, and distribution of the grains in ceramics, in order to improve the mechanical properties [2]. Metal-matrix composites have been emerged as potential alternatives to conventional alloys in high-strength and stiffness applications. Cost is the key factor for their wider application in modern industry, although potential benefits in weight saving, and increase component life, and improved recyclability is a vital factor $[3,4]$. The ever-increasing fuel price has led to a renewed urgency of weight reduction in the aerospace and automotive sectors. In recent years, stringent requirements of material quality in automotive and aerospace industries have necessitated the development of lightweight aluminum alloys. Reinforcing of aluminum alloys with discontinuous second phase particles offers high strength, high modulus, superior wear resistance, good workability, desirable thermal expansion and isotropy [5-9]. Al- $\mathrm{SiC}_{\mathrm{p}}$ composites meet most of the requirements of automotive, electrical and aerospace industry [10-13]. A wide range of production techniques 
have developed for aluminum matrix composites. Metal matrix composites have generally produced, either by liquid metallurgy or powder metallurgy route. Of these processes, forging is of high technical and economic interest because it avoids problems such as the need for special tools (expensive diamond-tipped inserts) during machining, poor mechanical properties because of reactions between some ceramic reinforcements and molten metal in casting, and the porosity in $\mathrm{P} / \mathrm{M}$ components. In the liquid metallurgy, the particulate phases have mechanically dispersed in the liquid before solidification of the melt. Among others, however, the powder metallurgy $(\mathrm{P} / \mathrm{M})$ method has known as a very promising route, which is most attractive due to several reasons. Firstly, in $\mathrm{P} / \mathrm{M}$ technique microstructural control of the phases is possible (Figure 1). Secondly, the lower temperatures employed during the process accounts for the strict control of interphase kinetics. In the $\mathrm{P} / \mathrm{M}$ method, the starting powders can be elemental or prealloyed. However, it is difficult to take advantage of both these requirements because they are prone to cause an inhomogeneous distribution. Poor distribution of reinforcement degrades the composites in terms of its physical and mechanical properties and negates the attractiveness of reinforcement additions. Using elemental powders are not only economical, but also bring an extra advantage to modify the matrix composition easily [14-17]. The presence of SiC particles accelerated the aging process due to the increased dislocation density, which provides more sites for the nucleation of precipitates. Metal matrix composites reinforced by ceramic particles, with low density, high strength and modulus and flexible fabricating techniques, have received particular attention in the past decades. Meanwhile, the particular preparation techniques of the composites rely on these factors [18-20]. Fracture of the matrix between the clusters of reinforcing particles, coupled with particle failure by cracking and

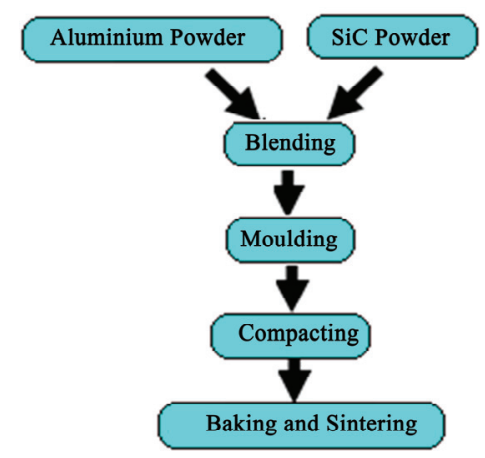

Figure 1. Various steps involved in synthesis of $\mathrm{Al}-\mathrm{SiCp}$ composites in $\mathbf{P} / \mathrm{M}$ technique. decohesion at the matrix/particle interfaces allows the microscopic cracks to grow rapidly and link resulting in macroscopic failure and resultant low tensile ductility.

However, little scientific evidence is available on the forgeability $\mathrm{P} / \mathrm{M}$ metal matrix composites. The present paper explains the forgeability and mechanical properties of $\mathrm{P} / \mathrm{M}$ MMCs at different weight fraction of $\mathrm{SiC}_{\mathrm{p}}$. The forging conditions have chosen to be similar to those necessary for mass production, and so a mechanical press has used. In addition, the mechanical properties of the unworked materials have also investigated because of these. In the present study, the nature of changing density, hardness and forgeability of $\mathrm{Al}-\mathrm{SiC}_{\mathrm{p}} \mathrm{MMCs}$ with changing of $\mathrm{wt} \%$ of $\mathrm{SiC}_{\mathrm{p}}$ has been investigated.

\section{Composite Production}

\subsection{Material}

Air atomized aluminium powder (average particle size of 400 mesh) reinforced with $\mathrm{SiC}$ particulates (Figure 2) (average size of 400 mesh) are used as the test material along with commercially pure aluminium. Aluminium matrix composites having 5, 10, 15 and $20 \mathrm{wt} \%$ fraction of $\mathrm{SiC}$ particles were used as the test material along with commercially pure aluminium. The above composites and aluminium has fabricated by powder metallurgy technique.

\subsection{Blending}

The metal and ceramic powders were blended in a drum with a cylindrical mixer (diameter $40 \mathrm{~mm}$, height 35 $\mathrm{mm}$ ), at a constant speed of $1500 \mathrm{rpm}$ for $1 \mathrm{~h}$. Blending is one of the crucial processes in $\mathrm{P} / \mathrm{M}$ where the metallic powders have mixed with the ceramic reinforced particles. Good blending produces no agglomeration of both the metallic and ceramic particle powders. To achieve this, several parameters such as particle size, blending speed and duration have taken into consideration to ensure the $\mathrm{SiC}$ particles distributing homogeneously in the matrix powders. The powder blending parameters have listed in listed in Table 1.

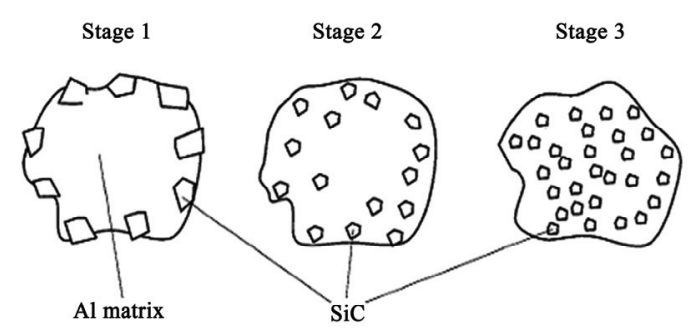

Figure 2. A schematic view of the evolution of distribution of the SiC particulates in Al matrix. 
Table 1. Powder blending parameters.

\begin{tabular}{ccccc}
\hline Mixture & $\begin{array}{c}\text { Filling of } \\
\text { mixer(vol.\%) }\end{array}$ & Operation & R.P.M & Time(min) \\
\hline 400mesh pure & 50 & Blending & 1500 & 10 \\
Al,400mesh & 75 & Blending & 1500 & 10 \\
SiC and & 100 & Blending & 1500 & 10 \\
Binder (Zinc & & Rest & & 15 \\
Stearate) & & Blending & 1500 & 15 \\
\hline
\end{tabular}

\subsection{Compacting}

A mixture of the particles and the binder (Zinc Stearate) has poured into a cylindrical die with $110 \mathrm{~mm}$ high, 25 $\mathrm{mm}$ inner diameter and $75 \mathrm{~mm}$ outer diameter. After pouring, the powder mixture was cold isopressed at 215 Kgf pressure with a hydraulic press (Manual Type, Capacity $800 \mathrm{Kgf}$. Ram stroke $300 \mathrm{~mm}$.) for 5 min to obtain green compacts. The hydraulic press and metallic die with it's punch are shown in Figures 3 and 4.

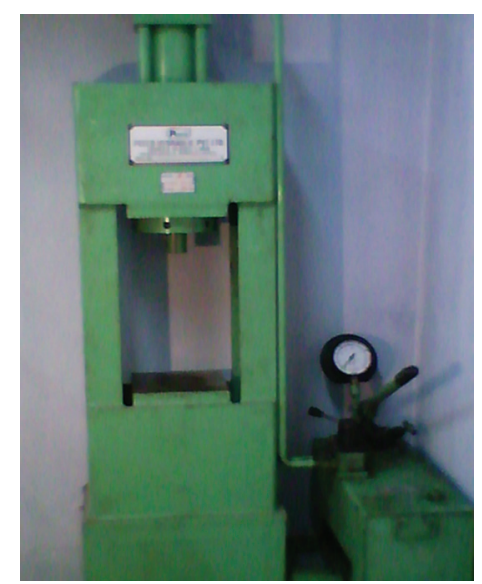

Figure3. Manual type hydraulic press.

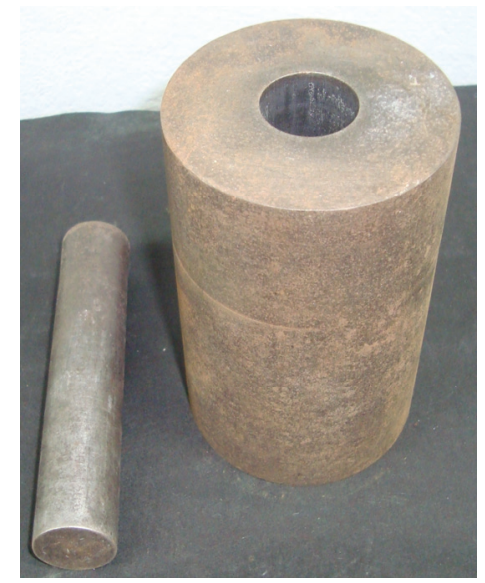

Figure 4. Metallic die with punch.

\subsection{Sintering}

The green compacts are then subsequently baked at $300^{\circ} \mathrm{C}$ and followed by sintering in a induction type floor stand tube vacuum furnace (Figure 5) (dia of hot zone 75 $\mathrm{mm}$ length of hot zone $150 \mathrm{~mm}$ and maximum temp $1450^{\circ} \mathrm{C}$ ). During processing, the matrix powders have exposed to atmosphere, which contains oxygen and moisture also, and it would oxidize at high temperature. Moreover, the moisture would react chemically with the oxide, and such reaction would reduce the bonding force of $\mathrm{Al}-\mathrm{SiC}_{\mathrm{p}}$ interface and further deteriorate the mechanical properties of the composites. Thus, the degassing should carry out in an environment of elevated temperatures and high vacuum, where the dew point and the oxygen partial pressure are low. The adsorbed compounds will evacuate and further oxidation can suppressed effectively.

To avoid the oxidation of Al alloy powders at high temperature and to abbreviate the preparation procedures, the degassing and sintering procedures of the green compacts have incorporated together. The stepped heating procedures of the degassing and sintering has introduced into the experiment. The sintering parameters have given in the Table 2

At the low temperature stages, the atmosphere and moisture could extract out, while the crystallized water would evaporate during sintering at the high temperature stages. The sintering at a normal pressure usually has a little influence on the $\mathrm{Al}-\mathrm{SiC}_{\mathrm{p}}$ interfacial cohesion due to the presence of an oxide layer on the Al powder surfaces. Therefore, an advanced sintering has carried out at the elevated temperature and high pressure to get the better interfacial cohesion. As it is well known, the matrix alloy will react with $\mathrm{SiC}$ particles or the interfacial layer will become thicker at over-elevated temperatures because of the intense atomic diffusion, and the matrix will lose its strength at high temperatures, a suitable temperature for the high pressure sintering should selected in this process.

\section{Results and Discussion}

\subsection{Micro structural Examination and Phase Analyses}

The samples (Figures 6 and 7) have prepared and examined

Table 2. Sintering parameters.

\begin{tabular}{|cccc}
\hline \multirow{2}{*}{ Operation } & \multicolumn{2}{c}{ Temperature } & \multirow{2}{*}{ Duration } \\
\hline Heating & Ambient $\left(30^{\circ} \mathrm{C}\right)$ & $300^{\circ} \mathrm{C}$ & $40 \mathrm{~min}$ \\
Soaking & $300^{\circ} \mathrm{C}$ & $300^{\circ} \mathrm{C}$ & $30 \mathrm{~min}$ \\
Heating & $300^{\circ} \mathrm{C}$ & $500^{\circ} \mathrm{C}$ & $30 \mathrm{~min}$ \\
Soaking & $500^{\circ} \mathrm{C}$ & $500^{\circ} \mathrm{C}$ & $30 \mathrm{~min}$ \\
Heating & $500^{\circ} \mathrm{C}$ & $750^{\circ} \mathrm{C}$ & $30 \mathrm{~min}$ \\
Soaking & $750^{\circ} \mathrm{C}$ & $750^{\circ} \mathrm{C}$ & $40 \mathrm{~min}$ \\
Cooling in furnace & $750^{\circ} \mathrm{C}$ & Ambient $\left(30^{\circ} \mathrm{C}\right)$ & \\
\hline
\end{tabular}




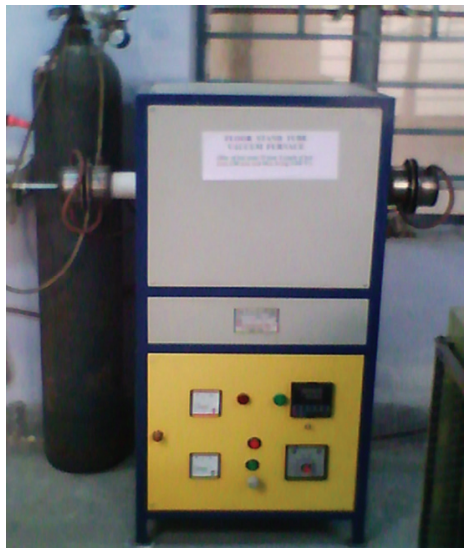

Figure 5.Induction type floor stand tube vacuum furnace.

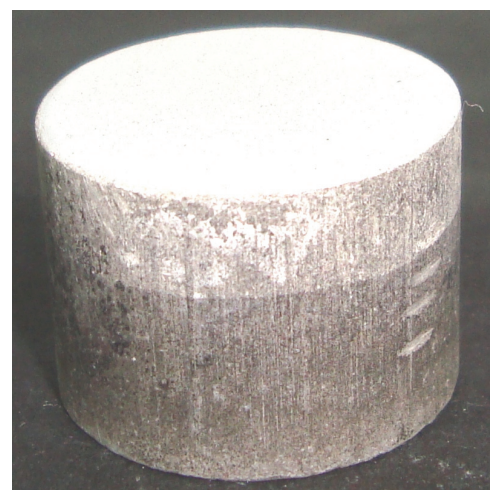

Figure 6. Sample before sintering.

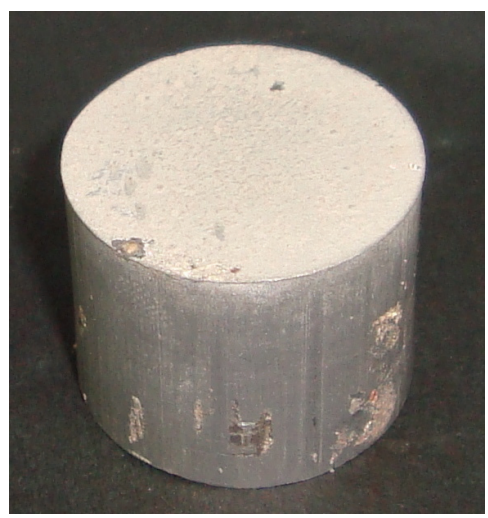

Figure 7. Sample after sintering.

by an optical microscopy. Samples for metallographic examination has prepared by grinding through 320,400 , $600,800,1200$ and 1500 grit papers followed by polishing with $6-\mu \mathrm{m}$

diamond paste. Then the samples have etched with the etchant $(2.5 \mathrm{ml}$ Nitric acid, $15.0 \mathrm{ml} \mathrm{Hcl}, 1.0 \mathrm{ml} \mathrm{HF}$ and $95.0 \mathrm{ml}$ Water). The etched samples were dried and the microstructure observed by using microscope (Olympus,
CK40M) at different magnification.

Figures 8-12(A) and (B) shows the fractograph and metallograph of the cold isopressed green compacts and followed by sintered Al-SiCp composites. So far, it indicates that the plastic deformation is beneficial to improve the homogeneity of the reinforcement. The presence of $\mathrm{SiC}$ particles can be detrimental to the ultimate compressive strength of the composite materials because of the addition to the possible failure mechanisms of unreinforced aluminum alloy of particle cracking, particle ma-
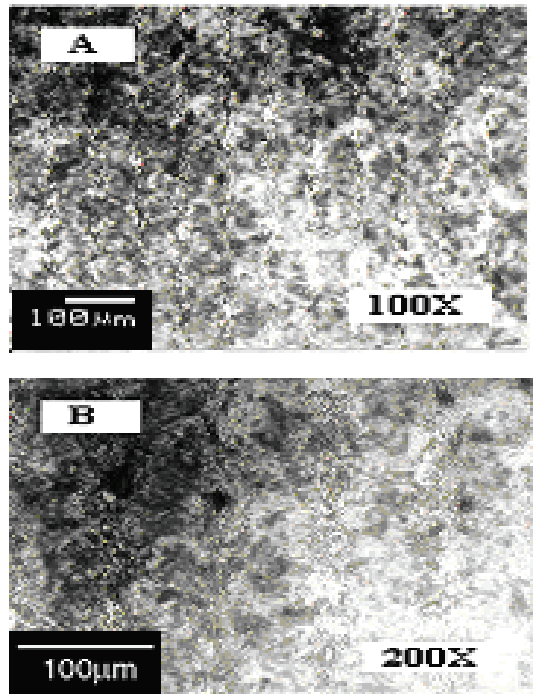

Figure 8. A\&B optical micrographs of the metal matrix composites pure Al.
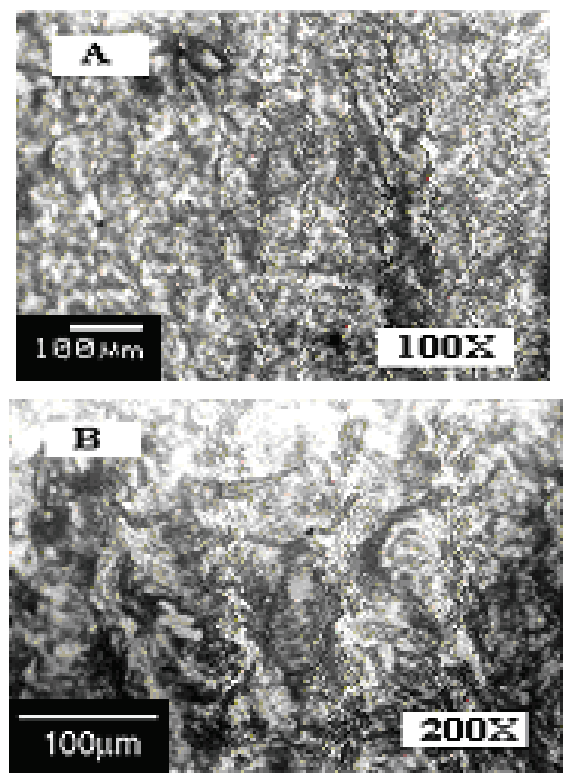

Figure 9. A\&B Optical micrographs of the metal matrix composites Al\&5 wt\% SiC. 


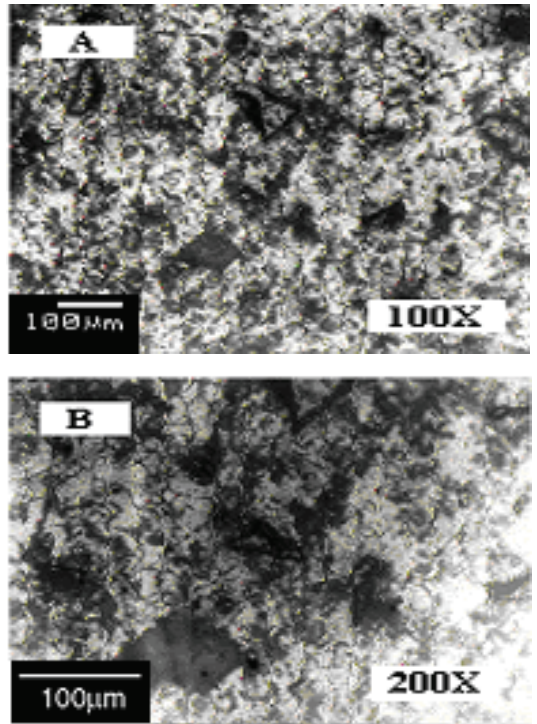

Figure 10. A\&B Optical micrographs of the metal matrix composites Al\&10-wt\%SiC.
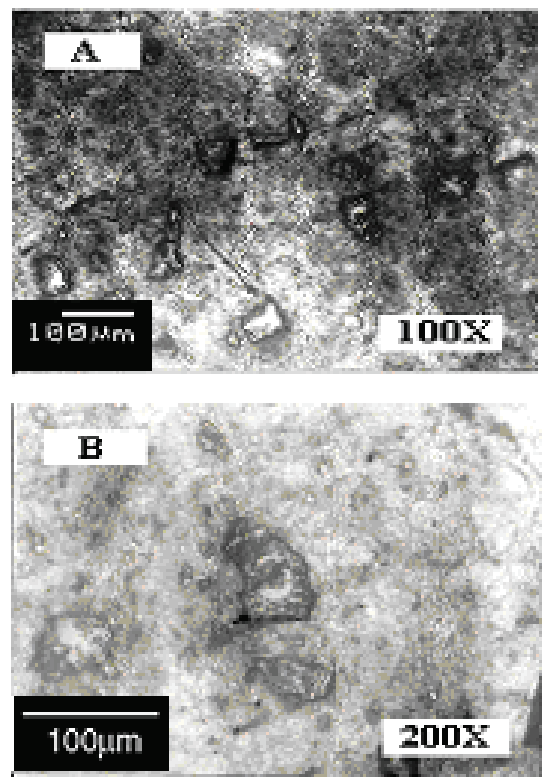

Figure 11. A\&B Optical micrographs of the metal matrix composites Al \&15wt\%SiC.

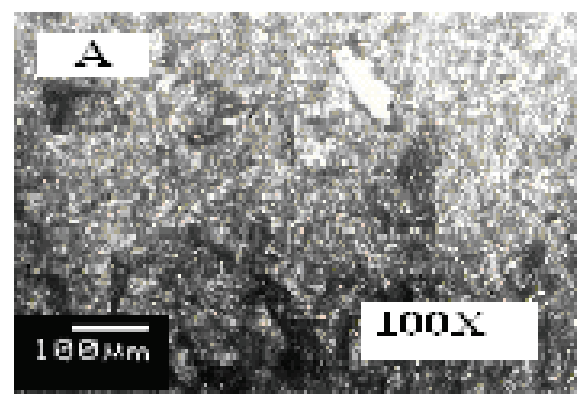

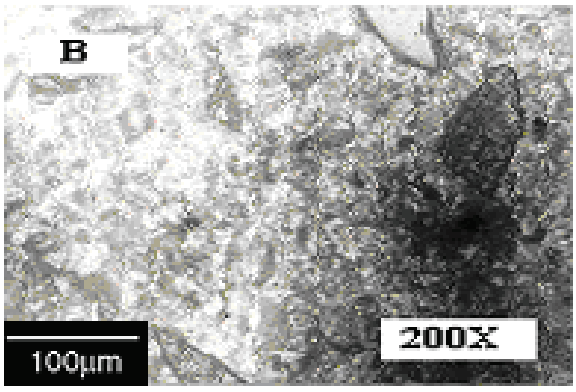

Figure 12. A\&B Optical micrographs of the metal matrix composites Al\&20wt\%SiC.

trix debonding and particle agglomerate decohesion. The latter two mechanisms are of secondary importance when the particles are well distributed and strongly bonded. Particles enhance the relative density of the materials and refine the metal matrix grains, which consequentially result in the increase of mechanical properties of the composites.

\subsection{Mechanical Properties}

\subsubsection{Density Measurement}

The density of the composites was obtained by the Archimedian principle of weighing the sample first in air and then in water. Then, theoretical density of composite and its alloy has calculated from the chemical analysis data. The measured relative density of the compacts was about $81.2 \%$. The gain refinement of metal matrix-based composites reinforced by tough particles can interpret by the increased effective extrusion ratio with increasing volume fraction of incompressible reinforcements. The density of the composites has shown in Figure 13. Since the density of $\mathrm{SiC}\left(3.215 \mathrm{gm} / \mathrm{cm}^{3}\right)$ is higher than that of the Aluminium $\left(2.7 \mathrm{gm} / \mathrm{cm}^{3}\right)$, the addition of $\mathrm{SiC}$ leads to an increase in the density of the material as long as the reinforcements are uniformly distributed in the matrix and no SiC clusters are formed. Reinforcement concen-

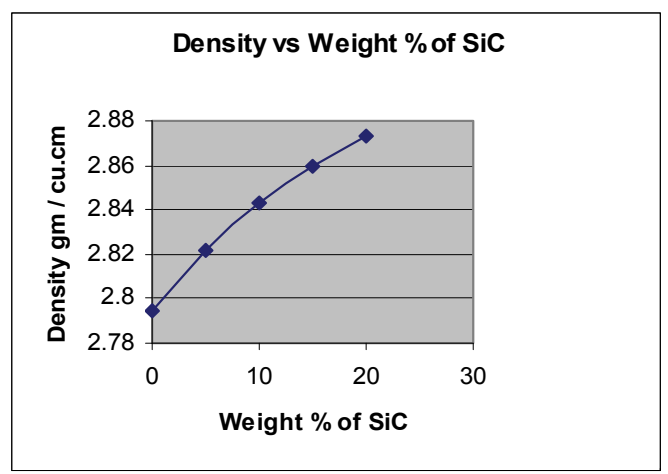

Figure 13. Relation between density and wt\% of $\mathrm{SiC}$ in Al-SiCp composites. 
trations of about $5-10 \mathrm{wt} . \%$ of $\mathrm{SiC}$ and $10-15 \mathrm{wt} . \%$ of $\mathrm{SiC}$, leading to a decrease in the density despite the increase in the $\mathrm{SiC}$ content in the composite

\subsubsection{Hardness Measurement:}

The hardness of the composites and matrix alloy has measured after polishing to a 6- $\mu \mathrm{m}$ finish. In composites, hardness increases proportionally by increasing the weight percentage of reinforcement particle. The Figure 14 shows that, hardness value changed due to variation of reinforcement ratio. Hardness of composites increases proportionally with the increase of the weight percentage of reinforcement particle.

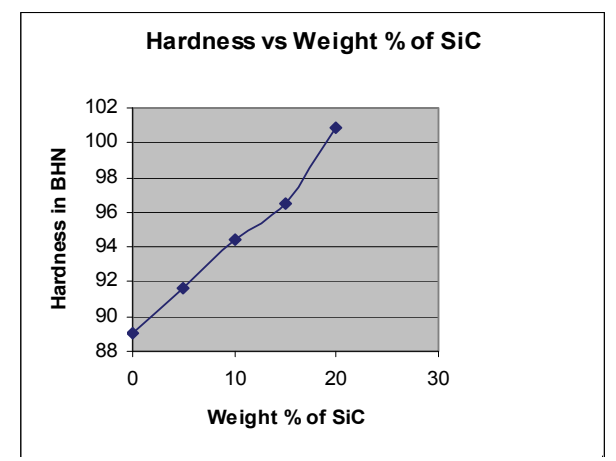

Figure 14. Relation between hardness and $\mathrm{wt} \%$ of $\mathrm{SiCp}$ in Al-SiC composites.

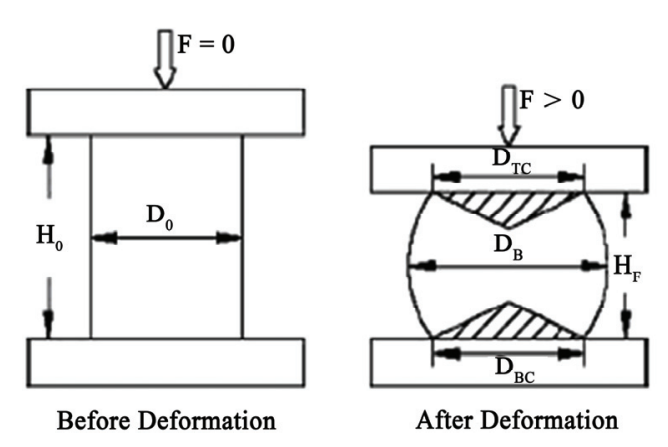

Figure 15. Forgeability test.

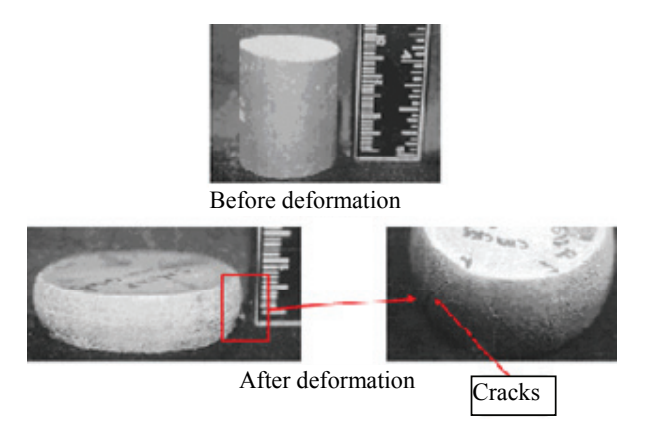

Figure 16. Photographs showing perform of before and after deformation test.

\section{Forgeability and Fracture Characteristics}

The limit of forgeability is expressed as the critical reduction in height $\%$ crit, by the following equation [21]:

$$
\% \text { Cirt }=\frac{\mathrm{H}_{\mathrm{F}}-\mathrm{H}_{0}}{\mathrm{H}_{\mathrm{F}}}
$$

where $\left(\mathrm{H}_{\mathrm{O}}\right)$ is the initial height of the sample and Initial diameter is $\left(\mathrm{D}_{\mathrm{O}}\right)$ in $\mathrm{mm}$. After each interval of loading dimensional changes in the specimen such as $\left(\mathrm{H}_{\mathrm{F}}\right)$ is the final height of the sample in $\mathrm{mm}$ after deformation top contact diameter $\left(\mathrm{D}_{\mathrm{TC}}\right)$, bottom contact diameter $\left(\mathrm{D}_{\mathrm{BC}}\right)$, bulged diameter $\left(\mathrm{D}_{\mathrm{B}}\right)$.

Critical reductions under unlubricated conditions only have compared to assess the forgeability of the experimental materials. The impact load was applied at room temperature on samples of different section of as cast MMCs reinforced with $5 \mathrm{wt} \%, 10 \mathrm{wt} \%, 15 \mathrm{wt} \%$ and $20 \mathrm{wt} \% \mathrm{SiC}$.

At different load, the percentage of deformation investigated. These results have presented in Figure 17.

Thus, it is particle cracking that has a major influence on the ultimate compressive strength of $\mathrm{Al} / \mathrm{SiCp}$ composite materials. The Figure 17 shows that on increasing the weight percentage of silicon carbide particles in cast composites the percentage of deformation decreases that means the forgeability of cast composites decreases on increasing the reinforcement ratios.

\section{Conclusions}

In this study, density, hardness, forgeability characteristics of Aluminum reinforced with 5, 10, 15 and $20 \mathrm{wt} . \%$ of $\mathrm{SiC}$ was examined .The effect of $\mathrm{SiC}$ reinforcement ratio on the hardness and the forgeability of $\mathrm{Al}-\mathrm{SiCp}$ MMCs has been evaluated.

- The microstructural study indicates that there is uniform distribution of $\mathrm{SiC}$ in the metal matrix composite.

- About 5-10 wt.\% of $\mathrm{SiC}$ and $10-15$ wt.\% of $\mathrm{SiC}$,

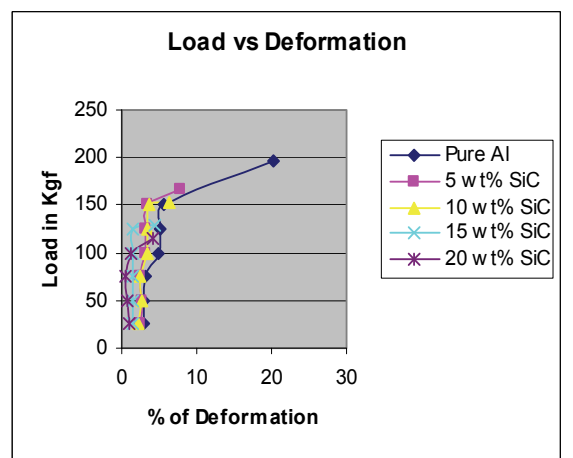

Figure 17. Relation between load and \% of deformation of Al-SiCp composites. 
leading to a decrease in the density despite the increase in the $\mathrm{SiC}$ content in the composite

- Hardness increases with the increase of weight $\%$ of $\mathrm{SiC}$ in the metal matrix composite.

- Forgeability of metal matrix composite is remarkably decreases with increase of weight $\%$ of $\mathrm{SiC}$ in metal matrix composite.

\section{Acknowledgements}

Authors thankfully acknowledge the financial support provided by U.G.C, New Delhi under Major Research Project Grant [F.No.-32-88/2006 (SR) dated 09.03.2007] without which this work could not be attempted.

\section{REFERENCES}

[1] J. H. Shyong and B. Derby, "The Deformation Characteristics of $\mathrm{SiC}$ Particulate-Reinforced Aluminium Alloy6061," Ov/brd OXI 3PH, 1994.

[2] O. Tatsuki, "Microstructural Design and Mechanical Properties of Porous Silicon Nitride Ceramics," Materials Science and Engineering: A, Vol. 498, No. 1-2, pp. 5-11

[3] O. Adem, A. Hatem and Y. Fevzi, "Production and Characterization of Silicon Carbide Particulate Reinforced Aluminium-Copper Alloy Matrix Composites by Direct Squeeze Casting Method," 54188, 2006.

[4] K. M. Shorowordi, T. Laoui, A. S. M. A. Haseeb, J. P. Celis and L. Froyen, "Microstructure and Interface Characteristics of $\mathrm{B} 4 \mathrm{C}, \mathrm{SiC}$ and $\mathrm{Al}_{2} \mathrm{O}_{3}$ Reinforced Al Matrix Composites: A Comparative Study," Journal of Material Processing Technology, Vol. 142, No. 3, 2003, pp. 738-743.

[5] P. Palash, V. C. Srivastava, P. K. De and K. L. Sahoo, "Processing and Mechanical Properties of SiC Reinforced Cast Magnesium Matrix Composites by Stir Casting Process," National Metallurgical Laboratory, Jamshedpur, 2007.

[6] S. M. S. Reihani, "Processing of Squeeze Cast Al6061-30vol\% SiC Composites and Their Characterization," Department of Materials Science and Engineering, Sharif University of Technology, Azadi Avenue, Tehran, 2004.

[7] K. Soma Raju, V. V. Bhanu Prasad, G. B. Rodrakshi and N. Ojha, "PM Processing of $\mathrm{Al}-\mathrm{Al}_{2} \mathrm{O}_{3}$ Composites and Their Characterization," Powder Metallurgy, Vol. 46, No. 3, 2003, pp. 219-223.
[8] B. Hwu, S. Lin and M. Jahn, "Effect of Process Parameters on the Properties of Squeeze Cast SiCp-6061 Al Metal Matrix Composite," Material Science Engineering A, Vol. 207, 1996, pp. 135-141.

[9] M. Gupta and M. K. Surappa, "Effect of Weight Percentage of SiC Particles on the Ageing Behavior of Al 6061/ SiC Metal Matrix Composites," Journal Material Science, Vol. 14, 1995, p. 283.

[10] H. Ahlatci, E. Candan and H. Cimenoglu, "Abrasive Wear Behavior and Mechanical Properties of $\mathrm{Al}-\mathrm{Si} / \mathrm{SiC}$ Composites," Istanbul Technical University, Maslak, Division of Metal Casting, Zonguldak, 2004.

[11] M. A. Martinez, A. Martin and J. Llorca, Metallurgica Scripta et Materialia, Vol. 28, 1993, pp. 207-212.

[12] Y. Chen and D. D. L. Chung, Journal Material Science, Vol. 29, 1994, pp. 6069-6075.

[13] V. V. Bhanuprasad, M. A. Staley, P. Ramakrishna and Y. R. Mahajan, Key Engineering Materials, 1995, pp 104-107, 495-506.

[14] B. Ogel and R. Gurbuz, "Microstructural Characterization and Tensile Properties of Hot Pressed Al-SiC Composites Prepared from Pure Al and Cu Powders," 2000.

[15] R. U. Vaidya and K. K. Chawla, In: K. Upadhya, Ed., Developments in Ceramic and Metal Matrix Composites, ASM International, Metals Park, 1991, p. 253.

[16] J. J. Lewandowski and C. Liu, In: P. Kumar, Ed., "Processing and Properties for Powder Metallurgy Composites," 1988, p. 117.

[17] W. C. Harrigan, Journal of Materials Science and Engineering, Vol. A244, 1998, p. 75.

[18] N.-P. Cheng, S.-M. Zheng, W.-B. Yu, Z.-Y. Liu, Z.-Q. Chen, "Deformation Behavior of SiC Particle Reinforced A1 Matrix Composites Based on EMA Model," Changsha, Chongqing, 2006.

[19] J.-Z. Fan and J.-M. Shang, "The Spatial Distribution of Reinforcements in Aluminum Matrix Composites," Acta Metall Sinica, Vol. 34, No. 11, 1998, pp. 1199-1204.

[20] G.-K. He and Q. Han, "Influence of Inclusion's Orientation and Spatial Distribution on Elastic-Plastic Properties of Composites," Journal of Beijing Institute Technology, Vol. 19, No. 5, 1999, pp. 554-559.

[21] K. S. See, "The Effects of the Disposition of SiC Particles on the Forgeability and Mechanical Properties of Co-Sprayed Aluminium-Based MMCs,” BI5 2TT, 1995. 